\title{
6 OPEN ACCESS \\ Are patients discharged with care? A qualitative study of perceptions and experiences of patients, family members and care providers
}

Gijs Hesselink, ${ }^{1}$ Maria Flink, ${ }^{2,3}$ Mariann Olsson, ${ }^{2,3}$ Paul Barach, ${ }^{4,5,6}$ Ewa Dudzik-Urbaniak, ${ }^{7}$ Carola Orrego, ${ }^{8}$ Giulio Toccafondi, ${ }^{9}$ Cor Kalkman, ${ }^{4}$ Julie K Johnson, ${ }^{10}$ Lisette Schoonhoven, ${ }^{1,11}$ Myrra Vernooij-Dassen, ${ }^{1,12,13}$ Hub Wollersheim, ${ }^{1}$ on behalf of the European HANDOVER Research Collaborative

For numbered affiliations see end of article.

Correspondence to Gijs Hesselink, Scientific Institute for Quality of Healthcare, Radboud University Nijmegen Medical Centre, P.0. Box 9101, 114 IQ healthcare, Nijmegen 6500 HB, The Netherlands; G.Hesselink@iq.umcn.nl

Accepted 11 August 2012 Published Online First 1 November 2012

\section{ABSTRACT}

Background: Advocates for quality and safety have called for healthcare that is patient-centred and decision-making that involves patients.

Objective: The aim of the paper is to explore the barriers and facilitators to patient-centred care in the hospital discharge process.

Methods: A qualitative study using purposive sampling of 192 individual interviews and 26 focus group interviews was conducted in five European Union countries with patients and/or family members, hospital physicians and nurses, and community general practitioners and nurses. A modified Grounded Theory approach was used to analyse the data.

Results: The barriers and facilitators were classified into 15 categories from which four themes emerged:

(1) healthcare providers do not sufficiently prioritise discharge consultations with patients and family members due to time restraints and competing care obligations;

(2) discharge communication varied from instructing patients and family members to shared decision-making;

(3) patients often feel unprepared for discharge, and postdischarge care is not tailored to individual patient needs and preferences; and (4) pressure on available hospital beds and community resources affect the discharge process.

Conclusions: Our findings suggest that involvement of patients and families in the preparations for discharge is determined by the extent to which care providers are willing and able to accommodate patients' and families' capabilities, needs and preferences. Future interventions should be directed at healthcare providers' attitudes and their organisation's leadership, with a focus on improving communication among care providers, patients and families, and between hospital and community care providers.

\section{BACKGROUND}

Patient-centredness has been advocated as a necessary element of high-quality healthcare. ${ }^{1-8}$ The US Institute of Medicine endorsed patient-centredness in 2001 as one of six goals for improving healthcare and as a powerful answer to address deficits in health systems in responding to patient-specific needs, preferences and values. ${ }^{9}$ Although a widely accepted definition of patientcentredness is lacking, ${ }^{5-8}$ most studies focus on aspects of understanding and respecting the patients' individual values, needs and desires; involving patients and family members in the care process, patient education and creation of shared knowledge; and physical and emotional comfort and support. ${ }^{10-15}$ Berwick described three maxims of patient-centredness: (1) 'The needs of the patient come first'; (2) 'Nothing about me without me' (ie, transparency and involvement of patients and family members in each clinical decision and in the design of the care process and services); and (3) 'Every patient is the only patient' (ie, a customisation of care at the level of the individual). ${ }^{16}$

Patient-centred care is considered to be especially important during critical episodes in the care process such as during discharge from the hospital. The growing emphasis on shorter hospital stays demands more postdischarge care and creates an important coordinating and management role for patients and family members. ${ }^{17}$ Often, patients and family members are the only common thread between hospital and community care services. ${ }^{18}$ Patients and family members require skills, information and confidence to ensure continuity in postdischarge care. ${ }^{18}$ Patients at discharge are often in a vulnerable state: they are anxious, have side effects from medication, and may have 
functional or cognitive impairment. ${ }^{18-20}$ Discharge can also be an intense episode in the care process where patients and family members are not ready to care for the patient at home, and are confronted with difficult decisions and changes (eg, financially and emotionally) that impact their home setting and resources.

Patients, despite the recently increased focus on patient-centredness, often leave the hospital unprepared for postdischarge demands. ${ }^{21-23}$ A recent survey of patients with complex care needs in 11 countries reported that one in four did not receive instructions for follow-up nor did they receive clear medication directions. ${ }^{24}$ Other studies have demonstrated that patients and family members express anxiety and a sense of abandonment after discharge. ${ }^{25-27}$ Patient unpreparedness, anxiety and a misunderstanding of the full ramifications of their situation at discharge are believed to increase hospital readmissions and adverse events in the posthospital setting. This is especially the case for the elderly and those with chronic conditions who require frequent transitions between hospital and home care. ${ }^{28-31}$

There is little understanding about the factors that facilitate or create barriers to patient-centred care at hospital discharge. Identifying the barriers and facilitators may help in the design of effective solutions for improving the discharge process. This may improve patients'/families' self-care skills (eg, improving medication adherence), mitigate patient anxiety, and reduce avoidable and costly readmissions.

The aim of this study was to explore the barriers and facilitators to patient-centred care in the hospital discharge process. We elicited perceptions and experiences about the discharge process through interviewing patients, family members and care providers (in the hospital and the community).

\section{METHODS}

\section{Study design and settings}

We conducted a qualitative study of patient handovers at hospital discharge in nine hospitals, and their respective primary and community care settings, as part of the HANDOVER project, which addresses patient handovers at the hospital to primary care interface in five European nations. ${ }^{32}$ The countries involved in the HANDOVER project (The Netherlands, Spain, Poland, Italy and Sweden) represent a wide variety and types of European healthcare and funding systems. Four academic or teaching hospitals and five regional community hospitals representing all five nations were selected to ensure the sample reflected a wide variation in hospital type, size and structure. Hospitals varied in size from 127 to 1042 beds.

\section{Participants}

Participants in the study were stakeholders in the discharge process, including patients and family members (if available), and healthcare providers (physicians, nurses) of the recruited patients at the hospital and community care settings. Patients recruited fulfilled both the general and country-specific inclusion criteria (table 1). We used purposive sampling to ensure diversity of patients (ie, age, gender, diagnosis, hospital setting and wards) and healthcare professionals. The patients or their proxy, if a patient was unable to

\begin{tabular}{|c|c|c|}
\hline & General inclusion & Country-specific inclusion \\
\hline $\begin{array}{l}\text { Patients and/or } \\
\text { family } \\
\text { members }\end{array}$ & $\begin{array}{l}\text { 18-years-old plus any of the } \\
\text { following diagnoses: diabetes } \\
\text { mellitus, asthma, COPD, chronic } \\
\text { heart failure and/or prescribed } \\
6+\text { drugs } \\
\text { Recruited consecutively at the point } \\
\text { of their hospital discharge } \\
\text { Discharged to the community } \\
\text { (ie, home or nursing home) }\end{array}$ & $\begin{array}{l}\text { The Netherlands: patients admitted to internal medicine, pulmonary } \\
\text { diseases, cardiology or (vascular) surgical wards } \\
\text { Spain: patients belonging to cultural minority groups with limited } \\
\text { health literacy (capacity to read, write and understand healthcare } \\
\text { information) } \\
\text { Poland: patients } \geq 60 \text { years of age } \\
\text { Italy: patients admitted to emergency ward } \\
\text { Sweden: patients admitted to emergency ward from emergency room. } \\
\text { If living at a nursing home, only within a geographically specified area }\end{array}$ \\
\hline $\begin{array}{l}\text { Hospital } \\
\text { physicians and } \\
\text { nurses }\end{array}$ & \multicolumn{2}{|c|}{ Internal medicine, pulmonary diseases, cardiology or (vascular) surgical wards } \\
\hline $\begin{array}{l}\text { GPs and } \\
\text { community } \\
\text { nurses } \\
\text { Exclusion criteria } \\
\text { Patients referrec }\end{array}$ & \multicolumn{2}{|c|}{ Representing the communities to which the patients were discharged } \\
\hline
\end{tabular}


participate personally due to his/her illness, were asked for written consent. Ethics approval was received at each of the five study sites. The providers were identified based on the patients they cared for and were then informed about the study and requested to participate.

\section{Development of interview formats}

The interview guides for the individual and focus group interviews were developed during several HANDOVER Research Consortium meetings. ${ }^{33}$ The questions for the individual interviews were pilot-tested and refined in each country and the results were used to create the final guide. Topics that guided the question development were:

- Experiences with recent discharge processes (appreciative/problematic situations and consequences)

- Perceptions about the discharge process in general (ie, experiences, beliefs, norms, assumptions, methods, tools, barriers, facilitators)

- Perceptions about role taking, tasks and responsibilities

- Thoughts and suggestions for improving the discharge process.

\section{Data collection}

The individual interviews were conducted with patients recently discharged from the hospital to the community (ie, nursing home or home) and with their hospital physician, hospital nurse, general practitioner (GP) and community nurse involved in the discharge process. Patients were approached before their discharge from hospital, and provided with information about the project, and the interviews were performed 3-4 weeks after discharge by two local research team members. All interviewers had experience and/or background in healthcare as researchers or as healthcare providers.

The focus group interviews were conducted separately with each stakeholder group, and varied in size from three to nine participants. The interviews were led by a trained moderator and one or two observers that completed field notes and added question prompts as needed. At the end of each focus group, the moderator summarised the discussion and allowed the participants to reflect and comment on the accuracy and validity of the information. ${ }^{34}$ All interviews were audio-taped and transcribed in the native languages according to a standardised format.

\section{Data analysis}

The analysis consisted of two parts: the general analysis at the national level of the interviews and a subanalysis of the cross national data (figure 1).

\section{General analysis}

The transcribed interviews were analysed using Grounded Theory, a qualitative research method focused on the identification of concepts that emerge from study interviews or observation. ${ }^{35}$ Two researchers in each country independently coded the transcripts to minimise subjectivity. Atlas.ti software V.6.0 (ATLAS.ti Scientific Software Development Company, GmbH, Berlin, Germany) was used to facilitate the coding process. Coding is the interpretative process in which conceptual labels are given to the data. ${ }^{35}$ The generated codes were circulated between researchers in all countries and the list of codes was developed into a shared codebook, during a face-to-face meeting, conference calls and electronic mail correspondence (available upon request). Agreement about the meaning of the in English developed codes was achieved before the analysis stage. Regular conference calls were held to refine the codebook as codes arose during the analyses and to group the codes that were related to the same phenomenon into unique categories. Country-specific codes were used as needed. The same two researchers further analysed the data in each country until conceptual saturation was reached for that country, that is, no new codes or categories were generated. ${ }^{35}$

\section{Synthesis of local analysis}

Local analyses were used to report on patient-centred care and the culture ${ }^{36}$ and to explore the barriers and facilitators to patient-centred care in the discharge process. Three researchers (GH, HW and MF) synthesised these findings. ${ }^{37}$ The categories and themes identified across the different settings were verified with the researchers from each country and an additional number of quotes from each country were provided to illustrate the findings. Finally, new hypotheses emerged as a result of the data from the local analyses. ${ }^{34}$

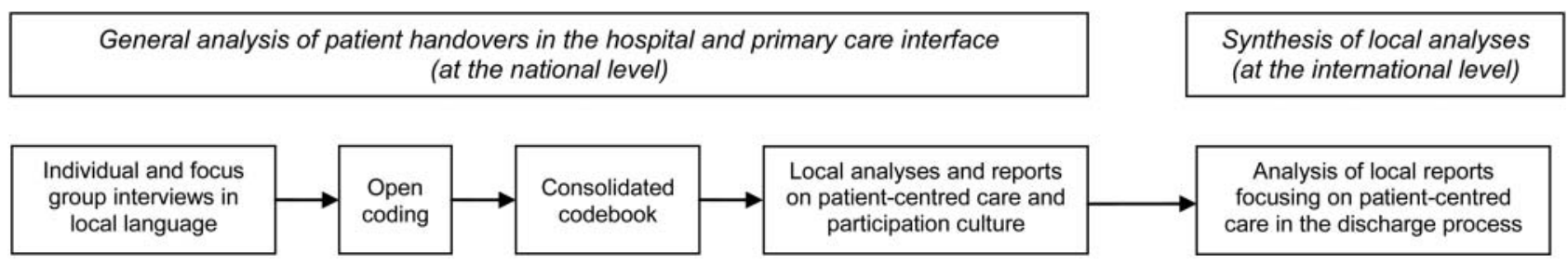

Figure 1 Procedure: from data collection to the subanalysis. 


\section{RESULTS}

Overall, 192 individual interviews and 26 focus group interviews were analysed regarding patient-centred care in the discharge process of the five countries. Individual interviews were conducted with 46 hospital physicians, 38 hospital nurses, 39 GPs and 16 community nurses. 53 patients and/or family members were interviewed. Of the patients recruited, 39 could not be interviewed for various reasons. The individual interviews were evenly distributed across the countries (table 2) and across age and gender groups.

The analysis resulted in 15 categories from which four themes emerged: (I) health provider prioritisation of discharge consultations; (II) decision-making within the discharge process; (III) care provider anticipation of patient-specific needs and preferences; and (IV) organisational factors (table 3).

\section{Theme I: care provider prioritisation of discharge consultations}

There are three categories within this theme: (1) lack of time; (2) giving priority to delivering medical or nursing care; and (3) lack of a standard discharge consultation.

\section{Lack of time}

The main concern for hospital physicians is delivering optimal medical care to patients, either for inpatients or outpatients. Hospital care providers, patients and their family members considered it important to complete the discharge consultations with the patient and family members during the hospitalisation period, and to discuss patient preferences and follow-up needs. Healthcare providers indicated that a barrier to optimal discharge consultations with patients and family members is a lack of time, with discharge often delegated to nurses or junior physicians. The consultations also take place at times that are convenient for the physicians, and these times often conflict with family member availability, which prevents them from being sufficiently informed.

\section{Giving priority to delivering medical or nursing care}

The responsibility to provide medical and nursing care to many patients and the interruptions by emergency admissions often leave care providers with insufficient time to talk with patients before they leave the hospital. Hospital nurses expressed that discharge consultations are frequently held in a rush just before patients leave the hospital, increasing the risk that important patient follow-up needs are missed or insufficiently addressed in the discharge process and the handover documentation prepared for community physicians and nurses. Patients then leave the hospital with incomplete information about care following the hospitalisation, including instructions for self-management.

\section{Lack of a standard discharge consultation}

Hospital physicians, nurses and GPs, frequently noted that at times a standard discharge consultation with patients and family members is not performed at all, especially for patients on surgical wards. Instead, the discharge information is provided piecemeal and in between other care activities. Consequently, patients, especially the elderly, often are not aware of the importance of the information provided, unable to remember the information and overwhelmed when they are suddenly told they have to leave the hospital.

Table 2 Number of interviews and participants (per country)

\begin{tabular}{|c|c|c|c|c|c|c|}
\hline \multirow[b]{2}{*}{ Country } & \multirow[b]{2}{*}{$\begin{array}{l}\text { Individual } \\
\text { Interviews (n) }\end{array}$} & \multicolumn{5}{|l|}{ Participants (n) } \\
\hline & & $\begin{array}{l}\text { Patients/family } \\
\text { members }\end{array}$ & $\begin{array}{l}\text { Hospital } \\
\text { physicians }\end{array}$ & $\begin{array}{l}\text { Hospital } \\
\text { nurses }\end{array}$ & $\begin{array}{l}\text { General } \\
\text { practitioners }\end{array}$ & $\begin{array}{l}\text { Community } \\
\text { nurses/other }\end{array}$ \\
\hline The Netherlands & 32 & 8 & 8 & 8 & 8 & - \\
\hline Spain & 30 & 8 & 6 & 5 & 7 & 4 \\
\hline Poland & 65 & 23 & 16 & 10 & 13 & 3 \\
\hline Italy & 27 & 5 & 7 & 6 & 5 & 4 \\
\hline Sweden & 38 & 9 & 9 & 9 & 6 & 5 \\
\hline \multirow[t]{2}{*}{ Total number } & 192 & 53 & 46 & 38 & 39 & 16 \\
\hline & $\begin{array}{l}\text { Focus group } \\
\text { interviews (n) }\end{array}$ & & & & & \\
\hline The Netherlands & 5 & 7 & 8 & 5 & 5 & 6 \\
\hline Spain & 5 & 3 & 8 & 6 & 9 & 7 \\
\hline Poland & 6 & $10^{*}$ & 4 & 7 & 4 & 7 \\
\hline Italy & 5 & 9 & 4 & 8 & 7 & - \\
\hline Sweden & 5 & 8 & 6 & 6 & 6 & 6 \\
\hline Total number & 26 & 37 & 30 & 32 & 31 & 26 \\
\hline
\end{tabular}


Table 3 Themes, categories and quotes related to handovers at patient discharge

\begin{tabular}{ll}
\hline Theme & Category \\
\hline $\begin{array}{l}\text { I. Care provider } \\
\text { prioritisation of } \\
\text { discharge } \\
\text { consultations }\end{array}$ & A lack of time \\
& \\
& \\
& $\begin{array}{l}\text { Giving priority to } \\
\text { delivering medical or } \\
\text { nursing care } \\
\text { Lack of a standard } \\
\text { discharge } \\
\text { consultation }\end{array}$
\end{tabular}

Representative quotes

Hospital physician: ...sometimes the discharge instructions do not go well enough. (...) because the intern is busy again or is called for an emergency. Meanwhile the patient cannot wait to go home. Well, at a certain moment you have to let the patient go.

Hospital nurse: There are communication gaps due to the rush everywhere. Sometimes a patient would like to ask a question, but (...) the physicians are in the operation room or away all day long.

Hospital physician: Our scope is restricted to pure medical care. (...) We are not very aware of how patients are discharged.

Hospital nurse: There is no specific discharge consultation with the patient. (...) Nurses talk a lot with patients during the whole day, but there is no specific moment when one says to the patient: "listen, I organised this and that".

GP: There are patients that are discharged and start complaining to me that they did not see the physician for two weeks and suddenly were informed with: "you can leave tomorrow". And on the next day there was no consult with the physician on duty. Nothing, but: "you can pack your belongings".

II. Decision-making within the discharge process

Involving patients in decisions regarding their follow-up

Dealing with competing interests

Estimating patients' resources, capabilities and skills

needs and skills

preferences
Patient: Three physicians arrived at my bed. My physician, the physician at the ward, and...then it is like: "your treatment here is over. We found a follow-up location for you. You can go." Actually, they force you (...) they are a bit authoritarian.

Community nurse: It is important to be sensitive to patient needs (...). But there is rush and insensitivity. It would be better if everyone, starting with the hospital physician, would ask the patient about what is needed.

Hospital physician: I will never keep the patient here against its will. If a patient does not want to go to a nursing home and even though the family (...) and nurses say: "he does not take care of himself and he will fall at home" (...) this person has the right to go home with the possibility to fall. (...) That the patient's autonomy.

Hospital nurse: I understand when a patient says: "I will not take these medicines". (...) But that is his own responsibility. Unfortunately we often see such patients returning to the hospital and unfortunately this happened in this case as well, because the patient did not take is blood thinning medicines... that's his own choice. (...) It [influence] stops when they leave the hospital door.

Patient: After the amputation of my toes I was sent home with two sets for wound care dressing and told to treat this by myself. (...) I got one bleeding after the other.

Community nurse: In several occasions patients have been discharged without us being informed about their insulin treatment, resulting in patients not receiving insulin after discharge. Sometimes it seems that the ward personnel thinks that these patients can manage everything by themselves and that they are all well functioning while, in reality, they suffer from dementia.

Patient emotions and emotional support Relative: It was clear that my mother was frightened to go home. A little more compassion and understanding would have made it much easier (...) Well, there was a consultation just before discharge, but it was a real technical-medical conversation. Not in the sense of "are you looking forward to go home?"

Patient: It was not possible to ask something because all the time you got the answer..."no this is not the right moment, later...".

Patient preparedness for discharge
GP: I often hear from patients that they were overwhelmed by the discharge, like: "suddenly I have to go home".

Hospital nurse: As soon as we talked about going home we saw that he panicked and got another asthma attack. We strongly had the feeling this was correlated with the fear to go home. You often see these patients quickly return to the hospital. I think: "this patient was not capable to go home" (...) apparently not with the right preconditions. For example, it would be better to 
Table 3 Continued

\begin{tabular}{ll}
\hline Theme & Category \\
\hline & \\
& $\begin{array}{l}\text { Quality of } \\
\text { information provided } \\
\text { at discharge to } \\
\text { patients and family } \\
\text { members }\end{array}$
\end{tabular}

Representative quotes

put those [COPD] patients back on the inhaler. (...) Now it often happens that patients are using a nebuliser in the morning, are discharged in the midday and have to continue with their own [different] inhalers at home while we did not see if they switch easily. And that is why often things go wrong.

Relative: We came back home with all this drugs without the slightest idea of how long the therapy was supposed to last.

GP: The hospital does not understand that information to the patient should be restricted to one page. I see patients arriving here with a complete set of brochures. (...) That is no information. (...) It only confuses or scares them. You should explain the few essential things.

Patient: So, the cardiologist stood next to me and said all sorts of things in Latin. (...) I do not speak Latin!

Exchange of patient-specific information between hospital and community care providers

Community care providers' role in monitoring patients after discharge

IV. Organisational factors
Shift work structures of hospital care providers

Accessibility of hospital care providers to patients

Pressure on available hospital beds

Discharges on weekends
Community nurse: $A$ hospital should inform us about patient discharge in case when a patient lives alone. These are elderly, sometimes with dementia. The doctor tells him things in the hospital, but the patient has already forgotten half of that when he gets home.

Hospital physician: We sometimes give information to the community nurse too late, really close to discharge and the community nurse does not have the time to organise the handover.

Community nurse: We see patients leaving the hospital with the medical report and they can have four ulcers...and not a soul knows about that! Until you visit them at home. That is very heavy.

Patient: To be honest I did not receive any calls from my GP and I would have appreciated it.

Hospital physician: The lack of consultations with patients and family at discharge has to do with work schedules of the attending physicians at the ward. (...) We have evening shifts, night shifts, weekend shifts. (...) The physician who takes over also needs time to get to know the patient. (...) This means that the information exchanged is not sufficient, because you do not know the patient well.

Patient: You constantly see new physicians (...) it makes you crazy, because at a certain moment you do not know who you need.

GP: I think a patient should have better access to the physician who still treats that patient. I mean, when this patient is recently discharged and still has a question related to his hospitalisation I think it is odd that it he is advised to contact the GP. At the outpatient clinic they say: "no, you cannot speak to the physician".

Hospital nurse: Sometimes you feel that the hospital physicians have made a decision about discharge, and then you feel that it is actually a little bit too early, actually. But you don't have that much of a choice since the pressure is high.

Hospital nurse: If a physician needs a hospital bed during the weekend, he or she will discharge the patient without any notification.

Patient: At Friday they told me that I could go home the next day. But the offices are closed on Saturdays and they could not give me all the proper discharge information and equipment. (...) That was not pleasant. (...) So I did the medication and all other things on my own.

GP, general practitioner.

\section{Theme II: decision-making within the discharge process}

Two categories emerged under this theme: (1) involving patients in decisions regarding their follow-up and (2) dealing with competing interests.

\section{Involving patients in decisions regarding their follow-up}

Comments on the involvement of patients in discharge handover decisions and decisions concerning follow-up varied widely. Some patients expressed that they had a 
voice in the choice of a nursing home or rehabilitation centre, whereas others felt they were ignored and only asked to follow their physicians' and nurses' instructions.

Patients experienced the decision about the timing of the discharge in varied ways. Several patients expressed that when they expressed that they did not feel ready to go home, they were allowed to stay in the hospital. Others felt they did not have any say in this matter or their requests were ignored. Patients and GPs mentioned instances of sudden and abrupt discharge that overwhelmed patients.

\section{Dealing with competing interests}

Physicians and nurses reported they face situations where patient preferences (eg, remaining in the hospital, not wanting to go to a nursing home) are in conflict with their medical, nursing needs or the administrative pressure of vacating hospital beds for other patients. Hospital physicians and nurses indicated that these problems may result in avoidable readmissions.

\section{Theme III: care provider anticipation of patient-specific needs and preferences}

Six categories emerged around this theme: (1) estimating patients' resources, capabilities and skills; (2) patient emotions and emotional support; (3) patient readiness for discharge; (4) quality of information provided at discharge to patients and family members; (5) exchange of patient-specific information between hospital and community care providers; and (6) community care providers' role in monitoring patients after discharge.

\section{Estimating patients' resources, capabilities and skills}

Patients and community care providers commented that patient-specific resources, self-management capabilities and skills are often overestimated or not critically assessed. As a result, patients may be discharged without sufficient medications or other supplies, or without detailed instructions to the patient or carers for how to perform simple procedures such as changing a wound dressing.

\section{Patient emotions and emotional support}

Hospital nurses in particular recognised the need for emotional support for patients at discharge. In contrast, patients and family members mentioned that there was little awareness of the patient's emotional status and needs by care providers, who rarely demonstrated compassion, efforts to listen to the patient, and to reassure patients and families about their concerns. Patients and family members perceived this as a small timeinvestment from care providers and commented that hospital physicians and nurses appeared to focus primarily on medical or nursing needs. Care providers commented on lack of time and normal care routines as barriers to more effectively addressing the emotional needs of patients and family members.

\section{Patient preparedness for discharge}

Care providers commented on the value of preparing patients for discharge, particularly those who need to perform more complex or technical care at home, and that more attention should be paid to encouraging patients to effectively perform monitored self-care activities in the hospital before discharge. However, patients and GPs also mentioned examples of sudden and abrupt discharge that overwhelmed patients. On the other hand, healthcare providers mentioned situations where they tried to prepare patients for discharge by informing them early in the day or hospitalisation about the expected discharge date or, if possible, by prolonging the hospital stay.

\section{Quality of information provided to patients and family members}

Hospital and community nurses, GPs and patients indicated that patients often receive insufficient instructions concerning their follow-up. For example, a patient who was required to inject a medication at home noted that no instructions or demonstration of how to inject the medication had been given before discharge. Information provided at discharge is often perceived to be unclear or it is given too fast with no time for questions or clarifications. Patients reported that healthcare professionals often used medical-technical jargon they were unable to understand, and community care providers reported that patients received an overload of nonprioritised written and verbal information at discharge, which lead to confusion and prevented patients from remembering key aspects of their follow-up care. Hospital nurses described various approaches to improve clarity of information and to ensure patients understood the most important aspects relevant to follow-up, including involving family members in discharge process, demonstrating and monitoring self-care activities, checking if patients understood the information and highlighting the important information in a discharge letter.

\section{Exchange of patient-specific information between hospital and community care providers}

Community care providers noted that the timely exchange of patient-specific information is important and supports anticipating patient preferences and needs at discharge. Descriptions of patients' social and emotional status (ie, living alone, dementia symptoms, 
depression, agitation) were reported to be important in addressing specific follow-up care needs. Several community care providers noted that this type of key information often is not present or deficient.

\section{Community care providers' role in monitoring patients after discharge}

Finally, patients and GPs believe it is important that community care providers check with patients whether there are unresolved issues to be dealt with. Patients indicated that this frequently does not happen and GPs concurred. GPs admitted this likely has to do with a lack of time and resources.

\section{Theme IV: organisational factors}

Four categories related to this theme: (1) shift work structures of the hospital care providers; (2) accessibility of hospital care providers to patients; (3) pressure on available hospital beds; and (4) discharges on weekends.

\section{Shift work structures of hospital care providers}

Hospital care providers indicated that the lack of discharge consultations with patients and family members relates to the structure of hospital physicians' and nurses' work shifts. Patient discharge is often performed by physicians and nurses who do not have an ongoing relationship with the patient or family. Care providers and patients described patients being discharged by care providers who just started their shift or rotation and were not acquainted with the patient's history, needs for community services or preferences. The involvement of multiple personnel sometimes also causes confusion at discharge as patients received contradicting information from different members of the healthcare team.

\section{Accessibility of hospital care providers to patients}

Hospital nurses, patients and GPs mentioned difficulties in identifying and contacting the physician or nurse who treated them in the hospital. Patients are often advised to contact their GP, while GPs are not always up-to-date with the treatment that was provided and the follow-up that was advised during the hospitalisation.

\section{Pressure on available hospital beds}

One factor reported by hospital care providers in pushing for early discharges was financial drivers and the lack of available hospital beds that requires patients to be discharged, even when the patients may not be ready to go home.

\section{Discharges on weekends}

A particular problem involved patients discharged just before or during the weekend. Although hospital care providers expressed these discharge situations require specific attention, patients and their GPs experienced problems with receiving immediate home care, equipment and medication during out of office and weekend hours. Moreover, the window of opportunity to arrange the necessary community care is small as discharge planning is decided or conveyed very late during the patient's hospitalisation.

\section{DISCUSSION}

To our knowledge, this is the first study that investigated patient-centred practice at hospital discharge based on the perceptions and experiences of patients, family members and care providers in the hospital and community. Patients, family members and care providers report various factors that facilitate or present barriers to patient-centred care in the hospital discharge process. Four themes emerged from this study: care provider prioritisation of discharge consultations; decision-making within the discharge process; care provider anticipation of patient-specific needs and preferences; and the role of organisational factors.

Our findings indicate that to a considerable extent patient-centred care is influenced by the behaviours of the health professionals and by organisational aspects beyond the direct influence of these professionals (ie, organisational factors). Our results suggest that both domains are intertwined. In the context of the three maxims of patient-centredness, ${ }^{16}$ our findings indicate that in the discharge process the needs of the patient do not often come first. Discharge planning occurs hurriedly just before the patient leaves the hospital, and a standard discharge consultation with the patient appears to be largely lacking. Interviews suggest this occurs due to a lack of time and the prioritisation by healthcare providers on providing urgent medical or nursing care to the patient or more likely to other patients.

Second, decisions about the patient are not always made with the patient. Decisions concerning discharge date and follow-up are made by healthcare providers without input of the patient or carers, often due to a lack of time and the pressure on available beds and available resources in the hospital and community. This likely is another important area for improvement, as studies demonstrate that the quality and safety of care and patient satisfaction increases, and healthcare costs decrease, when providers, patients and family members work in partnership. ${ }^{38-41}$

Third, many patients are discharged without specific information, instructions and without postdischarge care 
being tailored to their individual preferences and needs. This is due to an over or lack of estimation of the patient's capabilities, their degree of informal support and emotional needs. As a result, patients leave the hospital uninformed about the details of their posthospital care, and may feel unprepared and anxious. The patient's preparedness for discharge involves more than physical function readiness ${ }^{42}$ and should include also emotional, cognitive and psychosocial readiness, ${ }^{43} 44$ as well as the readiness of family members who will be caregivers. Many of the care providers recognise the importance of these aspects, but are often frustrated by their inability to discharge patients at the optimal moment, due to hospital bed availability for new patients and the limited availability of community care resources. Healthcare providers need to deal with conflicting pressures. ${ }^{45}$

Care providers informing patients about discharge repeatedly and in multiple-steps, providing information to patients about the expected discharge date early in the hospitalisation, and checking if patients understood the information were perceived as important facilitators to patient-centred care in the discharge process. Finally, patient and healthcare provider experiences demonstrate that it is essential that the GP and community nurses are informed well before the actual discharge date about the patient's hospitalisation history, home setting, emotional needs and eventual discharge plan. This will help ensure continuity of care with community care providers able to provide postdischarge care that helps to reduce the likelihood of unnecessary hospital readmissions.

Our study has several limitations. Patient-centred care was analysed and compared between the five countries that have their own distinct healthcare delivery and funding systems. These systems have unique legislative and organisational characteristics, and perform within different constraints while serving different patient populations. Not all findings were found across all five study sites. For example, we did not find comments on patient involvement in decision-making in the data from Spain. Spanish patients participating in the study were members of ethnic minority groups with low health literacy, which may contribute to differences in the desire for involvement.

Second, the interviews were transcribed in the native languages of the five countries, which may have increased the chances of errors and variations in the interpretation of the data. ${ }^{46}$ All efforts were made to ensure the methodological rigour and validity of the translations from English to the native languages as well as back to English across the study sites by using a standardised code book, meeting frequently, sharing and comparing our results, and by performing a pilot analysis. Finally, local influences on the quality of patientcentred care may be underappreciated and our findings may not be generalisable to other healthcare systems.
Future interventions at enhancing patient preparedness for discharge should be directed both at the level of the care provider's attitudes and at their organisational level, with a focus on improving the interactions among care providers, patients and family members, as well as to improving the interactions between hospital and community care providers. One intervention to be tested is a standard discharge handover protocol to offer patients and healthcare professionals a well thought out approach to these handovers. Additional promising interventions consistent with our findings include: educating and training care providers on aspects of patient-centred care, ${ }^{4748}$ and a formalised face-to-face discharge consultation, in an interruption-free location, for patients who are about to be discharged. The patients should be assessed for their level of understanding and to repeat or elaborate information. ${ }^{49-51}$ Specific tools to facilitate the information exchange to patients and family members might include the use of pictures, video and storyboards. ${ }^{52} 53$ Electronic notifications can be used to communicate the patient's medical and psychosocial information, in time, to community care providers. ${ }^{54} 55$ These initiatives can improve patient preparedness, reliability of patient care and greatly enhance the value of healthcare. ${ }^{5657}$

\section{CONCLUSIONS}

This study considerably improves our understanding of barriers and facilitators that can help or compromise patient preparedness for the discharge process. The use of individual and focus group interviews provided valuable insights into attitudinal and external aspects that influence patient-centred care during the discharge process. Overlooking these facilitators and barriers can often undermine the success of clinical interventions that have been used to address handover inefficiencies. ${ }^{58} 59$ Patient-centred discharge care processes should address two types of interactions: interactions among the care provider, patient and their family members, and the interactions between the hospital and community care providers. We hypothesise that the quality of these interactions is determined by the extent to which care providers, driven by their attitudes and their organisation of care, are willing and able to accommodate patient-specific needs and preferences.

\section{Author affiliations}

${ }^{1}$ Scientific Institute for Quality of Healthcare (IQ healthcare), Radboud University Nijmegen Medical Centre, Nijmegen, The Netherlands

${ }^{2}$ Department of Neurobiology, Care Sciences and Society, Karolinska Institutet, Stockholm, Sweden

${ }^{3}$ Department of Social Work, Karolinska University Hospital, Stockholm, Sweden

${ }^{4}$ Patient Safety Center, University Medical Center Utrecht, Utrecht, The Netherlands

${ }^{5}$ Department of Health Studies, University of Stavanger, Stavanger, Norway 
${ }^{6}$ School of Medicine, University College Cork, Cork, Ireland

${ }^{7}$ National Center for Quality Assessment in Health Care, Krakow, Poland

${ }^{8}$ Avedis Donabedian Institute, Universidad Autónoma de Barcelona and CIBER Epidemiology and Public Health (CIBERESP), Barcelona, Spain

${ }^{9}$ Clinical Risk Management and Patient Safety Centre, GRC, Tuscany Region, Florence Fl, Italy

${ }^{10}$ Centre for Clinical Governance Research in Health, University of New South Wales, Sydney, New South Wales, Australia

${ }^{11}$ Faculty of Health Sciences, University of Southampton, Southampton, UK

${ }^{12}$ Department of Primary Care, Radboud University Nijmegen Medical Centre, Nijmegen, The Netherlands

${ }^{13}$ Kalorama Foundation, Nijmegen, The Netherlands

Acknowledgements We thank all the healthcare providers, patients and their family members who participated in this study.

The European HANDOVER Research Collaborative consists of Venneri F, Molisso A (Azienda Sanitaria Firenze, Italy), Albolino S, Toccafondi G (Clinical Risk Management and Patient Safety Center, Tuscany Region, Italy), Barach P, Gademan P, Göbel B, Johnson J, Kalkman C, Pijnenborg L (Patient Safety Center, University Medical Center Utrecht, Utrecht, The Netherlands), Wollersheim H, Hesselink G, Schoonhoven L, Vernooij-Dassen M, Zegers M (Scientific Institute for Quality of Healthcare, Radboud University Nijmegen Medical Centre, Nijmegen, The Netherlands), Boshuizen E, Drachsler H, Kicken W, van der Klink M, Stoyanov S (Centre for Learning Sciences and Technologies, Open University, Heerlen, the Netherlands), Kutryba B, Dudzik-Urbaniak E, Kalinowski M, Kutaj-Wasikowska H (National Center for Quality Assessment in Health Care, Krakow, Poland), Suñol R, Groene 0, Orrego C (Avedis Donabedian Institute, Universidad Autónoma de Barcelona, Barcelona, Spain), Öhlén G, Airosa F, Bergenbrant S, Flink M, Hansagi H, Olsson M (Karolinska University Hospital, Stockholm, Sweden), Lilford R, Chen Y-F, Novielli N, Manaseki-Holland S (University of Birmingham, Birmingham, UK).

Contributors All authors had full access to all of the data in the study and can take responsibility for the integrity of the data and the accuracy of the data analysis. Study design: GH, MF, MO, PB, JKJ, LS, MVD and HW. Acquisition of data: GH, MF, ED-U, CO and GT. Analysis and interpretation of data: GH, MF, MO, PB, ED-U, CO, GT, JKJ, LS, MVD and HW. Drafting of the manuscript: $\mathrm{GH}$ and MF. Critical revision of the manuscript for important intellectual content: GH, MF, MO, PB, CK, JKJ, LS, MVD and HW. Study supervision: MO, LS, MVD and HW.

Funding This study was supported by a grant from the European Union, the Framework Programme of the European Commission (FP7-HEALTH-F22008-223409). The study sponsor had no role in the study design; collection, analysis and interpretation of the data; or in the writing of the article and decision to submit the article for publication.

Competing interests None.

Ethics approval Ethics approval provided by an Ethics Committee within each participating country.

Provenance and peer review Not commissioned; externally peer reviewed.

Data sharing statement Data are available on request from the corresponding author.

Open Access This is an Open Access article distributed in accordance with the Creative Commons Attribution Non Commercial (CC BY-NC 3.0) license, which permits others to distribute, remix, adapt, build upon this work noncommercially, and license their derivative works on different terms, provided the original work is properly cited and the use is non-commercial. See: http:// creativecommons.org/licenses/by-nc/3.0/

\section{REFERENCES}

1. Winefield $\mathrm{H}$, Murrell $\mathrm{T}$, Clifford $\mathrm{J}$, et al. The search for reliable and valid measures of patientcentredness. Psychol Health 1996;11:811-24.

2. Mead N, Bower P. Measuring patient-centeredness: a comparison of three observation-based instruments. Patient Educ Couns 2000;39:71-80
3. Mead N, Bower P. Patient-centredness: a conceptual framework and review of the empirical literature. Soc Sci Med 2000;51:1087-110.

4. Stewart M. Towards a global definition of patient centered care. BMJ 2001;233:444-5.

5. Mead N, Bower P. Patient-centered consultations and outcomes in primary care: a review of the literature. Patient Educ Couns 2002;48:51-61.

6. Epstein RM, Franks P, Fiscella K, et al. Measuring patient-centered communication in patient-physician consultations: theoretical and practical issues. Soc Sci Med 2005;61:1516-28.

7. Wolf DM, Lehman L, Quinlin R, et al. Effect of patient-centered care on patient satisfaction and quality of care. J Nurs Care Qual 2008;23:316-21.

8. Epstein RM, Fiscella K, Lesser CS, et al. Why the nation needs a policy push on patient-centered health care. Health Aff 2010;29:1489-95.

9. Institute of Medicine. Crossing the quality chasm: a new health system for the twenty-first century. Washington: National Academies Press, 2001.

10. McCormack B. A conceptual framework for person-centred practice with older people. Int J Nurs Pract 2003;9:202-9.

11. ACSQHC. Patient-centered care: improving quality and safety by focusing care on patients and consumers. Discussion paper. Sydney: Draft for public consultation, 2010.

12. Gerteis M, Edgman-Levitan S, Daley J, et al. Through the patient's eyes: understanding and promoting patient-centered care. San Francisco: Jossey-Bass, 1993.

13. Goodrich J, Cornwell J. Seeing the person in the patient: the point of care review paper. London: The King's Fund, 2008:1-63.

14. Shaller D. Patient centered care: what does it take? USA: Picker Institute and The Commonwealth Fund, 2007.

15. Cronin C. Patient-centered care-an overview of definitions and concepts. Washington, DC: National Health Council, 2004.

16. Berwick DM. What 'patient-centered' should mean: confessions of an extremist. Health Aff 2009;28:w555-65.

17. Arora VM, Prochaska ML, Farnan JM, et al. Problems after discharge and understanding of communication with their primary care physicians among hospitalized seniors: a mixed methods study J Hosp Med 2010;5:385-91.

18. Coleman EA. Falling through the cracks: challenges and opportunities for improving transitional care for persons with continuous complex care needs. J Am Geriatr Soc 2003;51:549-55.

19. Naylor M, Bowles K, Brooten D. Patient problems and advanced practice nurse interventions during transitional care. Public Health Nurs 2000;17:94-102.

20. Coleman EA, Mahoney E, Parry C. Assessing the quality of preparation for post-hospital care from the patient's perspective: the care transitions measure. Med Care 2005;43:246-55.

21. Martens $\mathrm{KH}$. An ethnographic study of the process of medication discharge education (MDE). J Adv Nurs 1998;27:341-8.

22. Parry C, Coleman EA, Smith JD, et al. The care transitions intervention: a patient-centered approach to ensuring effective transfers between sites of geriatric care. Home Health Care Serv $Q$ 2003;22:1-17.

23. Bull MJ, Kane RL. Gaps in discharge planning. J Appl Gerontol 1996;15:486-500.

24. Schoen C, Osborn R, Squires D, et al. New 2011 survey of patients with complex care needs in eleven countries finds that care is often poorly coordinated. Health Aff 2011;30:2437-48.

25. Mistiaen $\mathrm{P}$, Duijnhouwer E, Wijkel D, et al. The problems of elderly people at home one week after discharge from an acute care setting. J Adv Nurs 1997;25:1233-40.

26. Slieper CF, Hyle LR, Rodriguez MA. Difficult discharge: lessons from the oncology setting. Am J Bioeth 2007;7:29-37.

27. Naylor MD. Transitional care of older adults. Annu Rev Nurs Res 2002;20:127-47.

28. Forster AJ, Clark HD, Menard A, et al. Adverse events among medical patients after discharge from hospital. CMAJ 2004;170:345-9.

29. Forster AJ, Murff HJ, Peterson JF, et al. The incidence and severity of adverse events affecting patients after discharge from the hospital. Ann Intern Med 2003;138:161-7.

30. Forster AJ, Murff HJ, Peterson JF, et al. Adverse drug events occurring following hospital discharge. J Gen Intern Med 2005;20:317-23.

31. Mistiaen P. Hospital discharge: problems and interventions (PhD thesis). NIVEL, 2007.

32. The HANDOVER Research Consortium project, FP7-HEALTH-F22008-223409, see http://www.handover.eu

33. Hansagi $\mathrm{H}$, Olsson M, Glas $\mathrm{S}$, et al. Report on the barriers and facilitators to effective handovers in the social, linguistic and technological context in which they take place. Utrecht, The Netherlands: Utrecht Medical Center, 2010. 
34. Cohen DJ, Crabtree BF. Evaluative criteria for qualitative research in health care: controversies and recommendations. Ann Fam Med 2008;6:331-9.

35. Corbin J, Strauss A. Grounded Theory Research: Procedures, Canons, and Evaluative Criteria. Qual Sociol 1990;13:3-21.

36. Hesselink G, Wollersheim $\mathrm{H}$, Barach $\mathrm{P}$, et al. Report on challenges in patient care and the factors that influence change in practice. Utrecht, The Netherlands: Utrecht Medical Center, for the European Union, 2010.

37. Zimmer L. Qualitative meta-synthesis: a question of dialoguing with texts. J Adv Nurs 2006;53:311-18.

38. The Commonwealth Fund. In focus: health care institutions are slowly learning to listen to customers. 2010. http://www. commonwealthfund.org/Content/Newsletters/Quality-Matters/2010/ February-March-2010.aspx?view=newsletter_print (accessed 27 Feb 2012).

39. Institute for Patient- and Family-Centered Care. Advancing the practice of patient- and family-centered care: how to get started. Bethesda: Institute for Patient- and Family Centered Care, 2008:1-28.

40. Longtin Y, Sax H, Leape LL, et al. Patient Participation: Current Knowledge and Applicability to Patient Safety. Mayo Clin Proc 2010;85:53-62.

41. Stewart M, Brown J, Donner A, et al. The impact of patient-centered care on outcomes. J Fam Pract 2000;49:796-804.

42. Anthony MK, Hudson-Barr DC. Successful patient discharge: A comprehensive model of facilitators and barriers. J Nurs Adm 1998;28:48-55.

43. Heine J, Koch S, Goldie P. Patients' experiences of readiness for discharge following a total hip replacement. Aust $J$ Physiother 2004;50:227-33

44. Miller JM, Piacentine LB, Weiss M. Coping difficulties after hospitalization. Clin Nurs Res 2008;17:278-96.

45. Connolly M, Grimshaw J, Dodd M, et al. Systems and people unde pressure: the discharge process in an acute hospital. J Clin Nurs 2009;18:549-58.

46. Larkin PJ, Dierckx de Casterlé B, Schotsmans P. Multilingual Translation Issues in Qualitative Research: Reflections on a Metaphorical Process. Qual Health Res 2007;17:468-76.
47. Lewin S, Skea Z, Entwistle VA, et al. Interventions for providers to promote a patient-centred approach in clinical consultations. Cochrane Database Syst Rev 2001;(4):CD003267.

48. Clarke CM, Persaud DD. Leading clinical handover improvement: a change strategy to implement best practices in the acute care setting. J Patient Saf 2011;7:11-8.

49. Clark HH, Brennan SE. Grounding in communication. In: Resnick LB, Levine JM, Teasley SD, eds. Perspectives on socially shared cognition. Washington: American Psychological Association, 1991:127-49.

50. Doak C, Doak L, Root J. Teaching patients with low literacy skills. 2nd edn. Philadelphia, PA: JB Lippincott, 1996.

51. Schillinger D, Piette J, Grumbach K, et al. Closing the loop. Physician communication with diabetic patients who have low health literacy. Arch Intern Med 2003;163:83-90.

52. Houts PS, Doak CC, Doak LG, et al. The role of pictures in improving health communication: A review of research on attention, comprehension, recall, and adherence. Patient Educ Couns 2006;61:173-90.

53. Katz MG, Kripalani S, Weiss BD. Use of pictorial aids in medication instructions: a review of the literature. Am J Health Syst Pharm 2006;63:2391-7.

54. Afilalo M, Lang E, Léger R, et al. Impact of a standardized communication system on continuity of care between family physicians and the emergency department. CJEM 2007:9:79-86.

55. Tripp JS. Development and evaluation of notifications to inform primary care providers of summary documentation for their patients' hospital visits. The University of Utah, [Dissertation]. Salt Lake City, UT: Univ of Utah; 2009

56. Barach P, Berwick DM. Patient safety and the reliability of health care systems. Ann Intern Med 2003;138:997-8.

57. Barach P, Moss F. Delivering safe health care. BMJ 2001;323 585-6.

58. Grol R, Grimshaw J. From best evidence to best practice: effective implementation of change in patients' care. Lancet 2003;362:1225-30.

59. Shekelle PG, Pronovost PJ, Wachter RM, et al. Advancing the science of patient safety. Ann Intern Med 2011;154:693-6. 